\title{
Aproximaciones a la figura de Walter Benjamin en la historia de la filosofía
}

\author{
Approaches to the figure of Walter Benjamin in the \\ history of philosophy
}

Aproximações à figura de Walter Benjamin na

história da filosofia

Mag. Martín Ríos López*

\begin{abstract}
RESUMEN
La obra de Walter Benjamin ha jugado un papel importante en la tradición filosófica de los últimos 40 años. Es indiscutible su penetración e influencia en diversas áreas, pero esto no siempre fue así. Muchas veces ha sido incomprendido y dejado al margen de las grandes tendencias de la época. Incluso su condición de filósofo ha sido sometida a diversos análisis. En este artículo proponemos un recorrido por esas dificultades y dar cuenta de los supuestos teóricos que constituyen la originalidad de su propuesta filosófica.
\end{abstract}

\section{SUMMARY}

Walter Benjamin's work has played an important role in the philosophical tradition over the last 40 years. His penetration and influence in various areas is indisputable, but this was not always the case. Often, it has been misunderstood and left out of the great trends of that era. Even his status as a philosopher has been subjected to various analyzes. In this article we propose a journey through these difficulties and give an account of
Palabras clave: tradición filosófica, Walter Benjamin, marxismo, judaísmo

Keywords: philosophical tradition, Walter Benjamin, Marxism, Judaism

\footnotetext{
* Chileno. Máster Universitario en Estudios Avanzados en Filosofía por la Universidad Complutense de Madrid, Magíster en Filosofía con mención en Pensamiento Contemporáneo por la Universidad de Valparaíso y DEA en Filosofía Universidad de Salamanca. Académico de la Universidad de Playa Ancha.

Contacto:martin.rios@upla.cl

ORCID: https://orcid.org/0000-0001-5756-3240
} 
the theoretical assumptions that constitute the originality of his philosophical proposal.

\section{RESUMO}

A obra de Walter Benjamin vem desempenhando um papel im-

Palavras-chave: portante na tradição filosófica dos últimos 40 anos. São indistradição filosófica, cutíveis sua penetração e influência em diversas áreas, mas isto nem sempre foi assim. Ele muitas vezes foi incompreendido e deixado à margem das grandes tendências da época. Inclusive, Walter Benjamin, marxismo, judaísmo sua condição de filósofo foi submetida a diversas análises. Neste artigo propomos um percurso através dessas dificuldades e apresentar as suposições teóricas que constituem a originalidade de sua proposta filosófica. 
"Yo soy judio y cuando vivo como persona consciente, vivo como un judio consciente" ${ }^{\prime}$.

\section{Preliminares}

Buena parte de la literatura que se ha esforzado por atender el pensamiento de Walter Benjamin en los últimos treinta años, ha insistido sistemáticamente en destacar ese episodio que acontece durante la segunda mitad de la década de los años veinte. Nos referimos a su fracaso por alcanzar su "habilitación docente" en la Universidad de Frankfurt. Siendo esto así, parece necesario entonces preguntarnos con qué objetivo se evoca una y otra vez. Se puede llegar a entender que esta obsesión por el "fracaso académico", cuando se refiere al ámbito puramente biográfico, se esgrime con la clara intención de ilustrar el hado trágico y desafortunado que pareció perseguirle toda su vida. En otras oportunidades este evento es utilizado más bien como un recurso anecdótico, que intenta dar cuenta de la deriva que fue adoptando el desarrollo de su pensamiento debido a determinados acontecimientos biográficos. Pero lo realmente interesante del asunto se podría explicar a partir de algunas interrogantes, tales como, por ejemplo: ¿cuáles fueron los motivos le llevaron a presentarse como candidato a dicha "habilitación"? ¿Cómo fue que $E l$ origen del "Trauerspiel" alemán no pudiera ser comprendido por la comisión habilitante, $\mathrm{y}$, a pesar de ello, terminara convirtiéndose en una de las obras referentes del siglo XX? ¿Cómo fue que ese n(h)ombre terminará convirtiéndose en una especie de "firma" ? $\mathrm{O}$, dicho de otro modo, ¿cómo hemos de entender a Walter Benjamin dentro

1 Benjamin, Walter. Carta dirigida a Ludwig Strauß y fechada en 1912. (Pangritz 1223).

2 La alusión a la noción de "firma" que hemos propuesto se encuentra vinculada estrechamente con la idea de "singularidad". En ese sentido, la "firma" es un signo que pretende remitir a un rasgo distintivo que, en tanto único, permite identificar. Pero, sobre todo si se piensa en la idea que "dar" o "pedir" una firma, es, a su vez, un modo de "ofrecer" o "recibir" garantías. La "firma" viene a ser entonces una suerte de respaldo o fundamento. Si recurrimos a la experiencia de la lengua alemana, nos encontramos con que lo que en castellano conocemos por "firma" se expresa como Unterschrift. Es una palabra compuesta por Schrift, que significa literalmente algo así como "letra a mano" (letra manuscrita); y Unter, que significa "bajo" o "lo subyacente": un fundamento de la letra. Volverse una "firma" en sentido figurado viene a entenderse como un fundamento, una base, una hipóstasis. La pregunta es: ¿ icómo fue que se produjo el doble ingreso al canon filosófico de la obra y, así también, del autor? 
de la historia de la filosofía? y, por ende, ¿cómo entender el alcance de su trabajo intelectual? Lo cierto es que Benjamin es un personaje que, producto de su obra, tiende a ofrecer fiera resistencia a todo intento de clasificación reduccionista. Todo empeño por situarlo ya en una u otra escuela filosófica, se encuentra condenada de antemano al fracaso más rotundo. En ese sentido, resulta oportuno sostener que su obra desborda los moldes de encasillamiento típico de manuales escolares. No resulta fácil, porque hay algo en su modo de escribir, así como de sus temáticas, que resulta un tanto ajeno a la tradición académica. Por ello nos parece necesario - y es de nuestro interéscomenzar por identificar el lugar que éste ocupa dentro de la filosofía. En un primer momento, saber en qué medida tiene sentido la discusión que se ha esmerado en explicar si el adjetivo de "filósofo" es o no el más apropiado para él. Esto último a la luz, por cierto, de sus inclinaciones intelectuales y de su particular forma de abordar la operación que significa la escritura para su obra.

Hannah Arendt, como lúcida conocedora de Benjamin ${ }^{3}$ y su obra, ha sido quien, en un libro de mediados de los años sesenta del siglo veinte que se intitula Hombres en tiempos de oscuridad ${ }^{4}$, se atrevió a ensayar una explicación - hasta cierto punto polémica- y que bien vale la pena detenerse a exponer (Arendt 2008). Dos son los ejes del asunto. Por un lado, sostiene que Benjamin no es un filósofo sino más bien un "hombre de letras". Y, por otro, que su trabajo intelectual tenía con Heidegger una afinidad aún mayor de lo que se pueda suponer a simple vista, mucho mayor incluso que con "sus amigos marxistas". Alusión esta última en tono absolutamente despectivo a la Escuela de Frankfurt en general y, en específico, a Theodor Adorno ${ }^{5}$ y

3 Esta afirmación, en orden al conocimiento de su obra y a ciertos aspectos importantes de la vida de Walter Benjamin, encuentran su confirmación no solo en la obra aludida, sino también a partir de los registros epistolares que ésta sostiene con Scholem (Arendt y Scholem 2018).

4

5 Resulta conocida la distancia que mantiene Arendt con parte la escuela de Frankfurt, a quienes considera como una "banda de cerdos". Opinión, según se supone, resultante de un encuentro "desastroso" con Adorno en 1930 (Traverso 220-221). De esta aversión puede dar también testimonio G. Scholem cuando afirma que "Hannah Arendt sentía frente a dicho círculo, y en particular frente a Horkheimer y Adorno, una profunda aversión, que era por lo demás recíproca" (Scholem 2007 325). Como último dato, parece conveniente contar con el testimonio de la propia Arendt. Para ello se hace necesario remitir a la carta que envía a Scholem desde Nueva York, el 25 de abril de 1942, donde le 
Max Horkheimer. Desprecio que incluso se extiende al propio Bertolt Brecht.

Un segundo momento consiste en reflexionar ese aspecto significativo que constituye su particular e incomprensible modo de abordar el trabajo de reflexión filosófica. Dificultad para algunos o incomprensión para otros como resultado de esa novedosa, y para muchos forzada o cuando menos heterodoxa, relación metodológica que establece Benjamin entre marxismo y judaísmo. En este sentido, valga consignar que, para alguno de sus amigos, como es el caso de Gershom Scholem, resulta difícil de comprender esa conversión al marxismo -incomprensión que alcanza en algunos momentos un nivel de inquietud por el devenir intelectual de Benjamin y, en otros, un abierto desencuentro con el horizonte especulativo por el que se inclinan sus trabajos-, cuestión que se puede colegir si se atiende a los diálogos resultantes de sus contactos epistolares (Benjamin y Scholem 113). Asunto que, por lo demás, y como veremos poco más adelante, redunda en el silencio que muchas veces produjo el trabajo de Benjamin, no solo en la dimensión académica, sino también en los círculos de amigos más próximos.

Un tercer momento que nos parece atendible a la hora de procurarnos una línea de reflexión en torno a comprender la dimensión particular que ocupa Walter Benjamin en la "historia de la filosofía", se encuentra a partir de ese "acto fallido" — podríamos decirlo así- que significa el fracaso de la "habilitación docente" y, con ello, su intento por incorporarse a la carrera académica. Un fracaso que, en buena forma, vino a reafirmar los silencios a los que tempranamente se vio expuesto su apuesta intelectual y que se extendieron durante toda su vida y poco tiempo más.

\section{Un devenir intelectual: el caso de Walter Benjamin}

La irrupción, consolidación y consiguiente validación del pensamiento de Benjamin en la escena oficial de la academia universitaria es, para el caso, bastante tardía. Considerando únicamente el dato cuan-

vuelve a poner al corriente, y en afán de reafirmación, el hecho de que "Usted ya conoce mi opinión sobre todo ese círculo, y debo decirle que todo lo que vi y escuché aquí no es precisamente lo más adecuado para modificar mi opinión" (Arendt y Scholem 50). 
titativo de que es un pensador perteneciente a la escena intelectual de la primera mitad del siglo XX y, más concretamente aún, hasta su suicidio en 1940. Podemos ver confirmada nuestra afirmación si atendemos a la tardanza o la notoria indiferencia, ya por la escasa o a veces nula recepción que tuvo su trabajo en el medio cultural de la Alemania de la época. Una indiferencia que, por lo general, se debió al carácter críptico que orientó su estilo de escritura, esto es, a contracorriente del modo usual y acostumbrado de la época. Todo ello dio paso a un silencio ensordecedor en buena parte del medio intelectual en el cual se desenvolvía -incluso de aquellos que se encontraban más próximos-, llevándolo, en buena medida, a convertirse en una suerte de outsider. Ejemplos para ilustrar esta situación hay bastantes. El 11 de abril de 1934 Gershom Scholem - en carta dirigida al propio Walter Benjamin, a propósito de las gestiones que se encontraba realizando éste con el fin de proveerle algunos encargos de parte de Salman Schocken ${ }^{6}$, todo en vistas a generar un continuo de ingresos debido a la difícil situación económica en la que se encontraba- le comenta abiertamente y sin ambages al propio Benjamin que, a esas alturas, era difícil albergar alguna esperanza cierta para concretar algún tipo de encargo, puesto que si bien "...se manifestó sobre lo que ha leído de ti con una mezcla de aprecio, admiración y decidido rechazo, a la vez que declaraba insistentemente no entender nada de la mayor parte" (Benjamin y Scholem 110). Por otro lado, si tenemos en consideración la apreciación de sus amistades y colaboradores, la opinión en torno al tema tampoco parece variar demasiado. Por el carril de su círculo más íntimo, como sería el caso de Bertolt Brecht, por ejemplo, habría que decir que éste se sentía profundamente molesto por el "elemento teológico" que se irradiaba en la producción intelectual de Benjamin. Del mismo modo y, por otra parte, Benjamin era presa de la incomprensión, puesto que "Horkheimer, al igual que otros colaboradores del instituto, apenas podían por entonces mostrar el menor interés por esos

6 Salman Schocken para 1934 era miembro de la Junta de la Universidad Hebrea de Jerusalén y, además, dueño del periódico Haaretz. Era, por lo demás, un importante e influyente editor. En 1915 había fundado, junto a Martin Buber, la revista sionista Der Jude y, en 1931, la editorial Schocken Verlag. Con anterioridad a la irrupción del nazismo era dueño, junto a su hermano, de la cadena de Grandes Almacenes Schocken. El edificio más destacado, construido para tales efectos, fue diseñado por Erich Mendelsohn y construido entre 1929 y 1930 en Chemnitz; un ejemplo característico de modernismo arquitectónico (Weitz 2009 201-292). 
temas, de modo que Adorno, en un plano totalmente secularizado, siguió respondiendo de forma positiva" (Scholem 2007 310). Aunque sabemos que esta atención y comprensión en torno al modus operan$d i$ de la escritura benjaminiana no es del todo complaciente. Por otro lado, y en cierta medida al margen de las experiencias desencontradas con sus más cercanos, habría necesidad de aquilatar la situación con otras situaciones que ilustran adecuadamente, y de modo muy semejante, el desconcierto de la producción intelectual de Benjamin. En 1926 recibió el encargo, por parte de la "Gran Enciclopedia Soviética”, de la elaboración de la entrada “Goethe” (Benjamin 2009 319-356), trabajo que le tomó poco más de dos años de elaboración y que concluyó en 1928. El resultado no pudo ser más desconcertante, puesto que estuvo por debajo de las expectativas de quienes habían realizado el encargo. En un primer momento su publicación fue aplazada y finalmente publicada recién un año más tarde, pero de un modo tal que la reelaboración fue de tal envergadura que resultó absolutamente extraña a Benjamin, por lo irreconocible del resultado. Los editores, al parecer, descontentos y -más que de seguro- extrañados por el modus benjaminiano, decidieron rehacer el trabajo encargado, de un modo tan radical que implicó, al fin y al cabo, rehacerlo por completo. Sumado a esto se pueden dedicar unas líneas a otro hecho que va en la misma sintonía, y que aporta datos significativos para comprender el curso de argumentación hasta ahora sostenido. Durante 1929 Benjamin recibe otro encargo, esta vez por parte de Jacob Klatzkin, quien, a nombre de la "Enciclopedia Judaica", le pide dedicarse a tratar el tema de "los judíos alemanes en la vida intelectual de los siglos XIX y XX" (Id. 425-436). Este trabajo estaba pensado para ser incluido dentro un concepto o entrada de mayor extensión que se refería a "Alemania". Este trabajo, al igual que el anterior, quedó por debajo de las expectativas de los contratantes, tanto así que también sufrió la intervención de los editores. El texto, como sabemos, fue finalmente publicado en 1930, pero en una versión reelaborada que contó con la participación del rabino Benno Jacob y de Nachum Goldman, y, en ese sentido, bastante lejos del modus scribendi benjaminiano. Por desgracia no se conserva la versión original, pero en una separata se encuentra una nota apuntada de puño y letra de Benjamin en la que avisa que es esa una "Versión muy abreviada, expurgada de todo lo esencial. En varios pasajes, el texto no lo he ni escrito ni lo he tampoco corregido" (Id. 425). 
De lo afirmado hasta este momento sería posible extraer las siguientes conclusiones. Por un lado, podemos sostener que la recepción de la obra de Benjamin estuvo lejos de tener lugar cuando este se encontraba con vida. Sus compañeros de viaje intelectual, provenientes de dos corrientes de tradición disímiles, como son el marxismo y el judaísmo, serán los interlocutores privilegiados y sobre todo críticos de esa tentativa metodológica que lleva adelante Benjamin. Tal es el caso de Adorno, por el lado de la tradición marxista, quien rechaza decididamente la aportación de Benjamin a la revista del Instituto, en la que se le había encargado un trabajo sobre Baudelaire. Los motivos de ese rechazo apuntan, en términos generales, a una aplicación burda y poco especulativa del marxismo. En carta fechada en Nueva York el 10 de noviembre de 1938 le expresa su sentir del siguiente modo: "Este trabajo no le representa a usted del modo como precisamente este trabajo debiera representarle. (...) me permito rogarle fervorosamente que renuncie a la publicación de la versión actual y que se ponga a escribir otra" (Benjamin y Adorno 274). O el desconcierto que provoca en Scholem ese trabajo intitulado El problema de la sociología del lenguaje, publicado en la misma revista del Instituto de Adorno y Horkheimer. El 19 de abril de 1934 se queja de manera amarga, al hacerle presente que "Hasta ahora no he entendido el artículo de la Zeitschrift für Sozialforschung. ¿Se trata acaso de un credo comunista? Y si no es así ¿qué es? He de confesarte que este año ya no tengo idea de dónde te sitúas" (Benjamin y Scholem 113). Pero no solo a los referentes intelectuales que son afines a sus intereses les cuesta comprender el decurso que han asumido sus reflexiones, sino que también existe incomprensión por parte de las tradiciones de las que hace uso para constituir su matriz metodológica. No hay enciclopedia, soviética ni judaica, que haya aceptado sin reparos los aportes intelectuales de Benjamin. Se convierte así en una suerte de errante en el panorama intelectual de la época. Su hibridismo metodológico le convierte en un incomprendido - o un "triste", como prefiere describirlo Susan Sontag, según determinan las costumbres francesas (118)—. A pesar de todo esto, y contrariamente a lo que cualquiera pudiese haber diagnosticado -incluso para las opiniones más optimistas-, estas "soledades del pensamiento benjaminiano" han ido quedando atrás, y con creces. Parece necesario convenir en el hecho de que es recién a partir de los años sesenta del siglo XX que los vientos de la suerte — que en vida le 
fueron tan esquivos- comienzan a soplar definitivamente en su favor. A tal punto ha llegado la recepción de la obra de Benjamin que hoy es un referente obligado en diversas áreas del conocimiento, como la estética, la filosofía, el arte, la literatura, etc., y, extrañamente - aunque quizás no tanto-, en las instancias formales que emanan de la institución universitaria a nivel planetario, como por ejemplo papers, tesis, proyectos de investigación financiados por organismos estatales o privados, congresos, publicaciones, etc. Pero más aún, a tal ha llegado su penetración cultural que incluso en la ciudad de Buenos Aires existe una Fundación Walter Benjamin, bajo cuyo alero cobra vida un Instituto de Comunicación y Culturas Contemporáneas, que imparte una serie de profesiones del área de las comunicaciones.

\section{Devenires: entre "filósofo" y "hombre de letras"}

\subsection{Entre la marginalidad y la fama (póstuma)}

La posición marginal que ocupó durante buena parte de su vida fue resultado del desarrollo de un itinerario cultural a contrapelo de las expresiones más características de la época. Hay conciencia de que fue un, casi, desconocido dentro de las referencias intelectuales de su momento histórico. El legado intelectual de Benjamin llega a nosotros gracias al cuidado de sus amistades más próximas. Sin esos diligentes cuidados, suponemos de modo verosímil, es probable que buena parte de su obra hubiese quedado en un inquietante olvido. La promoción de la obra de Benjamin, después de su suicidio en Portbou hacia fines de septiembre de 1940, se debió fundamentalmente y en igual medida, al empeño - por cierto, no ausente de tensiones- de tres figuras importantes en su vida, a saber, Gershom Scholem, Theodor Adorno y Hannah Arendt. La inquietud por rescatar, preservar y difundir el legado de "Benji" - como cariñosamente Hannah Arendt se refiere a él en sus cartas dirigidas a Scholem- es una constante. El 25 de abril de 1942 Arendt le manifiesta abiertamente esta inquietud, al señalar de modo enfático: "Estoy muy preocupada por la suerte de sus manuscritos" (Arendt y Scholem 50). Su preocupación la lleva incluso, poco después, a tomar cierta iniciativa sobre el curso de las diligencias que se deberían adoptar. En la misiva que dirige al mismo Scholem, y fechada esta vez el 14 de noviembre de 1943, busca que éste pueda interceder, ante el editor Schocken, a favor de alguna respuesta positiva 
a la posibilidad de publicar algo del desaparecido amigo en común. Le señala, casi en tono emotivo, que "Si pudiera interesar a Schocken en la publicación del legado, quizás se podría hacer algo" (Id. 57). Las incansables gestiones terminaron, para Benjamin, dándole una fama, aunque póstuma, ciertamente merecida. Sobre esta fama póstuma que precedió a Benjamin, dedica Arendt unas reflexiones en su libro Men in dark times de 1965, en un capítulo dedicado íntegramente a Benjamin. Atendiendo a lo característico de la fama, afirma Arendt, en tanto diosa codiciada, ésta tiende a manifestarse caracterizada por variados rostros, formas y tamaños. La fama póstuma, siendo una de las más raras, es, a la vez, una de las menos deseadas. Y, sin embargo, posee como virtud en contrapunto, el hecho de que es "menos arbitraria y a menudo más sólida que otros tipos, dado que sólo rara vez se concede como mercancía" (Arendt 161). La suerte de Benjamin, siempre fluctuante, va desde ser un conocido en su época, mas no un personaje propiamente famoso, hasta convertirse en alguien a quien le adviene, finalmente, una fama post mortem, que le convierte en un imprescindible de la academia, la misma que, en su momento, no fue capaz de otorgarle reconocimiento.

\subsection{Su relación con la academia}

Si bien por parte de la academia hubo poca receptividad para con el trabajo intelectual de Benjamin, no es menos cierto que ese desencuentro fue, en buena medida, casi una cuestión recíproca. Sus experiencias con las instituciones educativas siempre se le develaron, desde su más tierna mocedad, como terrenos extraños, áridos o poco aptos para un alma tímida y un cuerpo frágil. $\mathrm{Y}$, a la vez, esos mismos terrenos que se le ofrecían como inhóspitos para ser vividos, quizás fuesen un terreno sobre el que necesariamente le tocaba fijar la atención, porque era ahí donde buena parte de la tradición del siglo pasado aún seguía latiendo. Por ello, no resulta fuera de lugar afirmar que, desde sus primeras experiencias, nunca pudo llegar a sentirse del todo cómodo con aquellas instituciones educativas decimonónicas de inspiración Guillermina, "en cuyas clases los azotes, los vejámenes mediante cambio de asientos, los arrestos eran castigos habituales, llenó al alumno Benjamin de desazón y espanto" (Bernd 2002 18). Sobre aquel sistema educativo, recuerda Benjamin -en un pasaje de su libro Infancia en Berlín hacia el 1900, que lleva por título "Mañana de invierno" - las sensaciones 
que le inundaban todas las mañanas. Todas ellas del desánimo infantil con el que afrontaba el ritual de asistir cada día a clases. Esa "mañana de invierno", como lo característico de muchas, veía interrumpida la rutina del sueño por la niñera que, junto con despertar el fuego para calentar el espacio de la habitación, permitía también experimentar como despertaba, y en igual medida, se cansaba. Ese mismo cansancio que parecía remitir ante la escena de la manzana que previamente había sido arrojada sobre la salamandra y que ahora ofrecía el espectáculo de desaparecer a la vez que dejaba en el ambiente un olor con el cual "tenía la impresión de que esta imagen era suficiente para todo el día" (Benjamin 2010 190). Por un momento se animaba y tenía la impresión de poder soportar todo el día; no obstante, a pesar de todo, la realidad terminaba por imponer sus propias condiciones.

Era esa noticia que algunas veces me excitaba tanto que aún me consolaba de camino al colegio. Cuando llegaba allí, todo ese cansancio, que parecía desaparecido, volvía multiplicado por diez cuando me sentaba en el pupitre. $Y$, con el cansancio, reaparecía el deseo de dormir hasta hartarme. Sentí este deseo centenares de veces, y, más tardíamente se cumplió (Id. 190-191).

La figura del pedagogo y reformista Gustav Wyneken marcó un momento decisivo en el joven Benjamin. Tanto así que, bajo esa inspiración, llegó a participar del movimiento de las Comunidades Escolares Libres y, posteriormente, también del grupo llamado Jungendbewegung en las actividades de la Sprechsaal. En esos encuentros, recuerda Scholem “(...) se congregaban escolares y estudiantes que, particularmente decepcionados por la enseñanza académica «superior», aspiraban sobre todo a una transformación espiritual más profunda" (Scholem 2007 32), que se esperaba provocar a partir de una reforma escolar y universitaria. Esa reticencia por el sistema escolar y por la mayoría de sus profesores fue una constante durante su formación universitaria. Decepción que se extendió, incluso, cuando hubo la posibilidad de ingresar en ella a través de una habilitación docente. Pero previo a esta última situación — que dejamos para ser discutida con atención un poco más adelante en nuestro trabajo-, habría que describir las impresiones de Benjamin sobre el ambiente universitario en el cual le tocó formarse y lidiar. Ciertamente había, por parte de Benjamin, más de alguna distancia con la producción del devenir histórico, cultural 
e intelectual que acontecía en la academia universitaria. Sobre este asunto, Hans Meyer, en su particular libro Walter Benjamin. El contemporáneo, aporta un dato significativo y que nos permite hacernos una idea bastante ajustada al estado anímico —o de la opinión- con el cual Benjamin enfrentaba la academia. Escribe Meyer, a propósito de la impresión que le dejó a Ernst Bloch, en sus encuentros con Benjamin en la época en la cual éste se encontraba preparando su tesis doctoral en Suiza, que "(...) había sin duda mucho conocimiento y bastante menosprecio hacia la literatura y filosofía profesoral de aquel entonces" (Meyer 1992 32) $)^{7}$. Por esa misma época, pero esta vez a Scholem, y en plena sintonía con lo expresado a Bloch, le hacía notar su claro convencimiento en torno a que "nosotros (...) formábamos nuestra propia academia" (Scholem 2007 105). En torno a esa inquietud, podríamos decir que hubo un ejercicio ficticio que pretendía cubrir esa necesidad latente en Benjamin. Para eso fantasearon en torno a una academia imaginaria, la "Universidad de Muri", que, por lo demás, daba, en cierto sentido, rienda suelta a esa imperiosa necesidad juvenil, aún vigente por esos días en Suiza, de transformar su entorno cultural y político. El ímpetu de Benjamin en torno a tales temas - y que se encuentran en íntima sintonía con la ficción de la "Universidad de Muri" - quedan plasmados en el escrito Alegría y seriedad, en el que propone que la juventud “(...) debe aprender poco a poco a trabajar a tomarse en serio a sí misma, a educarse a sí misma, en la confianza en esa juventud muestra la humanidad su confianza en el futuro" (Meyer 1992 27). Esos juegos imaginarios sobre la fundación de la anterior aludida universidad eran compartidos de igual forma tanto con Gershom Scholem como con Ernst Bloch (Id. 105-106). En alguna medida, había una referencia explícita a ese idealismo de sus convicciones y aspiraciones juveniles, que se enfrentaba en abierta oposición a la tradición cultural de las generaciones anteriores. Ideas y aspiraciones que pretendían hacer posible un nuevo espacio de producción y desarrollo que diera cabida a un - también nuevo- sentido de la libertad: una ruptura que hiciera posible la desaparición de las ya decadentes formas culturales y políticas decimonónicas de raigambre Guillermina que atravesaban todas

7 Una opinión semejante sobre este asunto tiene Wolfram Eilenberger, quien afirma, coincidentemente con Hans Meyer, que "La actitud de Benjamin y Scholem ante el nivel de los cursos y seminarios locales era de menosprecio" (Eilenberger 2019 44). 
las formas de manifestación cultural y que, a través de la educación, encontraban un modo efectivo de pervivencia y difusión. La tradición Guillermina no era más que la profunda tradición prusiana, aquella que tenía tan afincado los valores bélico-militaristas concebidos en el seno de la tradicional clase burguesa de los terratenientes o Junkers de la Prusia Oriental.

\subsection{Sobre la condición de filósofo}

Si quisiéramos obtener una idea fidedigna acerca de las repercusiones que pudo o no haber tenido Walter Benjamin con sus aportes en diarios, revistas, la radiofonía y secciones literarias hasta antes de la ascensión de Hitler al poder, se podría recurrir a una voz como la de Hannah Arendt para hacernos una idea meridianamente acabada del asunto. En Hombres en tiempos de oscuridad afirma al respecto que "fue conocido, pero no famoso (...) pocos eran los que aún recordaban su nombre cuando eligió la muerte en aquellos primeros días de otoño de 1940" (Arendt 2008 161). Durante un lapso luego de su muerte, podría decirse que incluso dejó de ser conocido. Y, en cambio, hoy resulta una figura casi indispensable como referente de la cultura, las artes y la filosofía contemporánea. ¿Qué pasó entonces?

Ocurrió que hubo, después de todo, una aceptación de su obra por buena parte de la tradición académica y filosófica. Podría decirse que ha pasado a formar parte del panteón de los filósofos. Y, sin embargo, esta última afirmación no deja de portar algún grado de escepticismo, porque el trabajo de Benjamin es de difícil clasificación. Ello se podría deber, si seguimos la interpretación de Michael Löwy, al hecho que "su obra, en efecto, se presenta como una especie de bloque errático al margen de las grandes tendencias de la filosofía contemporánea" (2005 13). Hay que convenir -y como primera cuestión- en el hecho de que no es éste un filósofo al uso de las formas que dictamina la convención académica. No hay en su obra un canon irrestricto que le ubique sin discusión alguna en el campo de la filosofía. Podemos encontrar inclinaciones, además de las propiamente filosóficas, que se encuentran ligadas a temas de crítica literaria, estética, lenguaje, arte, cultura, etc.

Lo central, sin embargo, puede señalarse con claridad: Benjamin fue un filósofo. Lo fue en todas las fases de su actividad y en cada una de las formas que ésta adoptó. Visto desde fuera, escribía por 
lo general sobre asuntos de literatura y el arte, con frecuencia también acerca de fenómenos situados en la frontera de la literatura y la política y sólo raras veces sobre objetos reconocidos y juzgados convencionalmente como temas de filosofía pura. Pero, aun así, era movido por las experiencias del filósofo (Scholem 1998 15).

La afirmación de Scholem en torno al asunto se zanja en la expresión "aun así". Esto es, a pesar de todo, es un filósofo. Bajo esa salvaguarda del "aun así", algunos intérpretes de la obra de Benjamin parecen igualmente coincidir. Tal es el caso de Michel Löwy, quien prefiere asignarle el estatus de "inclasificable" (Löwy 12 y 13). Otros, como Theodor Adorno (244), no tienen reparo alguno en afirmar que Benjamin es, a secas, un filósofo. Pero, y a pesar de todo, hemos de tener en claro que el debate se encuentra servido. Ello porque una de las más lúcidas y tempranas conocedoras ${ }^{8}$ y reconocedoras de la significación de la obra de Benjamin es capaz de afirmar, a contracorriente de estos pensadores, que en modo alguno podría ser considerado un filósofo, sino más bien un "hombre de letras".

Para describir su trabajo en forma adecuada y a él como autor dentro de nuestro usual marco de referencias, tendría que hacer varias declaraciones negativas, tales como: su erudición fue grande, pero no era erudito; sus temas comprendían textos y su interpretación, pero no era un filólogo; no lo atraía mucho la religión pero sí la teología y el tipo de interpretación teleológica para la que el en sí es sagrado, pero no era teólogo y no sentía interés particular por La Biblia; era un escritor nato, pero su mayor ambición fue producir una obra que consistiera en citas; fue el primer alemán que tradujo a Proust junto con Franz Hessel y St. John Perse, y antes de eso había traducido los Tablaeux parisiens de Baudelaire, pero no era traductor; revisó varios libros y escribió una serie de ensayos sobre escritores vivos o muertos, pero no era crítico literario; escribió un libro sobre el barroco alemán y dejó un estudio sin terminar sobre el siglo XIX francés: trataré de demostrar que pensaba en forma poética, pero no era ni poeta ni filósofo (Arendt 2008163 y 164).

8 Así lo recuerda Scholem cuando, a fines de 1932, en Berlín, conoce a Hannah Arendt junto a su primer esposo, Günther Anders, y entiende que para ella "Benjamin parecía ya representar una autoridad intelectual de peso” (Scholem 2007288 y 289). 
Si no era ni "erudito", ni "filólogo", ni "teólogo", ni "traductor", ni "crítico literario", ni "poeta", ni "filósofo", entonces qué era. Un poco más adelante, en la lectura del escrito citado, encontramos la repuesta formulada bajo la siguiente expresión: "Nadie estaba preparado a sostenerlo en la única «posición» para la cual había nacido, la de homme de lettres (...)" (Id. 188). Dicho así, nos aprontamos a pensar cuando menos dos cosas. La primera y más evidente es que Benjamin no es un "filósofo" según los usos académicos más convencionales. Se puede afirmar que se mantuvo al margen de las tendencias de la época. Y esto también en un doble sentido. Primero, porque fue capaz de privilegiar la crítica por sobre un pensamiento sistemático y, en igual medida, por no dejarse someter a los imperativos que dictaminaba, como regla, el positivismo académico. $Y$, en segundo lugar, porque si bien se encontraba próximo al marxismo y al judaísmo - tendencias que en la Alemania del primer tercio del siglo eran relevantes- y sin olvidar, por cierto, la oleada positivista que se posesionaba como hegemónica en las prácticas científicas en su conjunto, ni marxistas ni sionistas fueron capaces de comprender a cabalidad el punto desde el cual Benjamin se dispuso a llevar a delante su trabajo intelectual. Si bien puede resultar enigmático, si no acaso también un tanto incomprensible, la formulación propuesta por Arendt, a la hora de interpretar el locus benjaminiano dentro del concierto esquemático de la actividad intelectual de aquel momento histórico, no nos parece ni antojadiza ni desafortunada. Un "hombre de letras" - que en otros términos puede llegar a ser entendido como un "dedicado a las letras": un literato- tiene, en el caso de Benjamin, una vocación empática por los avasallados, por los vencidos. La preeminencia crítica por la que apostó tempranamente Benjamin -en tanto homme de lettres - es una forma constante a lo largo de desempeño intelectual. A cualquier lector medianamente familiarizado con la obra de Benjamin le será plausible esta afirmación, sobre todo si tiene en la retina la obra correspondiente a la última década. Sin embargo, los registros de estas formas se anuncian desde muy temprano, tanto que - incluso de forma incipiente- se pueden colegir en el escrito no publicado en vida, pero concebido hacia fines de 1912 e inicios de 1913, Diálogos sobre la religiosidad del presente:

(...) estando al servicio de la humanidad como su redentor. (...) el estamento que hoy sufre esta esclavitud histórica. Los literatos quieren ser los más honestos, exponer su entusiasmo por el arte, 
"su amor a los lejanos", por decirlo con Nietzsche, pero la sociedad los rechaza, y así ellos mismos tienen que extirpar en una patológica autodestrucción (...) nuestra falsedad los condena a ser outsiders y a exagerar hasta volverse estériles (...) A esto nos ayudan los literatos y nos ayuda la nueva religión (Benjamin 2007 29).

Benjamin convierte la figura del "hombre de letras" en una experiencia que primeramente le permita pensar y actuar según su propia responsabilidad, y que tiene como su punto de partida en los avasallados. Bernd Witte sostiene que Benjamin concibe este "hombre de letras" en relación con la marginalidad judía, una especie figura de hombre límite del cual es menester esperar la salvación, puesto que "él mismo se reservaba el papel del hombre de letras que se proponía descifrar lo espiritual en todas las manifestaciones de la vida" (35). El "hombre de letras", por lo pronto, y a diferencia del tradicional filósofo académico, tiene una pretensión de vinculación activa con la historia y, en concreto, con aquellos que han sido avasallados. Sobre este tópico benjaminiano, más adelante podremos encontrar rasgos característicos que componen las ideas medulares de sus obras más tardías, como por ejemplo las Tesis sobre la historia. Desde muy temprano, Benjamin se dio a desarrollar una estrategia que le permitiera desplegar sus reflexiones a partir de un modelo crítico, en íntima sintonía con sus aspiraciones juveniles, que no desaparecieron nunca.

\section{La dimensión metodológica de su pensamiento: entre marxismo y judaísmo}

\subsection{Cuestiones de método}

Una de las dificultades en la recepción de la obra de Benjamin, tanto en los círculos intelectuales como académicos, o de amigos incluso próximos, se debe justamente a lo que comprendemos acá como su "estrategia metodológica de escritura". Sabemos que eso le significó cierta fama de pensador incomprensible, puesto que su literatura posee una forma de escritura hermética, en cierto aspecto esotérica, de difícil penetración hermenéutica y casi - se podría decir-comprensible sólo para algunos. Aquellos que se encuentran ya iniciados en la tradición del judaísmo, y quizás con cierto grado de conciencia sobre esta última afirmación nuestra, entenderán que Adorno se haya 
aventurado a caracterizar, como cuestión propia y singular de la escritura de Benjamin, aquel rasgo que va entre un carácter esotérico, en sus escritos juveniles, y lo fragmentario, si se presta atención a los trabajos que corresponden a su última etapa (Adorno 1962 244). Si nos adentramos un poco más en este asunto, resulta interesante una observación que en 1930 Benjamin hace tanto a Adorno como a Max Rychner ${ }^{9}$, y, debido a su importancia para lo que a continuación queremos explicar, no puede ser desatendida. Según esa anécdota Benjamin les habría comentado, a propósito del prólogo del Trauerspiel, que éste solo podría ser entendido por quienes se hubiesen iniciado en la Cábala. Un comentario como éste invita a dar por hecho que solo unos pocos - los iniciados-se encontrarían en condiciones intelectuales suficientes para proceder adecuadamente a su lectura y comprensión. Años más tarde el propio Adorno tiene la oportunidad de consultar a Scholem sobre el contenido de ese asunto. Para cierta sorpresa de ambos, éste recuerda que nunca Benjamin le hizo mención alguna acerca de ese asunto (Scholem 2007195 y 196). Lo que parece claro es que Benjamin, desde un principio, ha renunciado a toda forma de interpretación explícita. Exponer crítica o filosóficamente un asunto no puede - o no debe- ceñirse bajo el canon impuesto por el progresismo de las ciencias modernas que reduce todo a útil. Las grandes exposiciones universales son el momento festivo y sintomático de la época en el que se daban a conocer los avances tecnológicos a los que se puede aspirar en la cultura de masas, en un incipiente capitalismo del consumo (Marinas y Santamarina 2015). En ese asunto, Benjamin parece disentir de ciertas tendencias emergentes en el seno de las primeras décadas del siglo XX y finales del XIX. No se debe olvidar que, durante la primera mitad del siglo XX, uno de los métodos más influyentes en las prácticas filosóficas - sino el que más- fue la fenomenología de cuño husserliano, que lleva por lema emblemático "ir a las cosas mismas" (Husserl 1999 218). Husserl personalizaba un proyecto de práctica filosófica que había alcanzado cierto estado de desarrollo y prestigio en los círculos universitarios. Esta práctica filosófica de la fenomenología - y en cierta medida muy a juego con el estatus de influencia que había alcanzado

9 Crítico literario y ensayista. Colaborador en diversos periódicos y fundador en la ciudad de Zürich en 1939 del diario "Die Tat". 
el desarrollo científico positivista- pretendía devolverle ese carácter "científico" extraviado y que, sin embargo, la filosofía desde siempre había tenido. En 1911, en su libro La fenomenología como ciencia estricta, a propósito de esto afirma:

Desde sus primeros comienzos, la filosofía pretendió ser una ciencia estricta, más aún, la ciencia que satisfaga las necesidades teóricas más profundas y haga posible, desde el punto de vista éticoreligioso, una vida regida por normas puramente racionales. Esta pretensión fue sostenida en las diversas épocas de la historia con mayor o menor energía, pero jamás fue abandonada (1962 7).

Una pretensión que, por cierto, según Husserl, nunca fue abandonada por la filosofía. Era, entonces, un estado latente en la filosofía a lo largo de toda su existencia. Esto es, nunca la filosofía pretendió "olvidar" ${ }^{10}$ ese deseo de ser una ciencia. Las aspiraciones metodológicas de Benjamin encuentran un modo de definirse formalmente, desmarcándose de esa condición formal que exige la filosofía husserliana. En esa, según Adorno, "divergencia radical entre la conciencia social y la científico-natural” (245), Benjamin desde siempre pareció tomar partido por la primera, en desmedro de la segunda. He ahí que encontramos, entonces, un primer asomo de comprensión del marco teórico que, como problema, atiende a su metodología de pensamiento: ir más allá del cientificismo filosófico imperante de su época. Bernd Witte, a propósito de lo mismo, sostiene que "Benjamin establece la preeminencia de la crítica como modelo de conocimiento, sobre el pensamiento sistemático, que a sus ojos resulta inadecuado después de sus experiencias históricas de 1914" (54). Lo que acaba con la "Gran Guerra" no es tan solo un modelo político, sino que también un sistema, o, dicho de otro modo, ese pensamiento - el pensamiento como sistema- que era capaz de articular determinadas lógicas de producción y comprensión de la realidad. El fin de la Gran Guerra parece que solo se encarga de levantar acta (de defunción) de un acontecimiento que ya ha sucedido. Esto es, vendría a significar, como contrapartida, el fin de las condiciones de posibilidad sobre las cuales se inscribió.

10 A propósito de este "olvido", probablemente en un registro distinto, será precisamente Martin Heidegger quien tomará el testigo de esta cuestión en 1927, en su obra Ser y Tiempo. 


\subsection{Un método sin sistema}

Ahora bien, su estrategia metodológica no se encuentra entre las tendencias que tienen por fuente de inspiración la pretensión de hacer de la filosofía una ciencia estricta y, con ello, tampoco siquiera aproximarse a desarrollar un sistema filosófico, esto es, un cúmulo de ideas coherentes y cohesionadas en sí mismas, de modo tal de ofrecer una explicación "sistemática" y universal. En Benjamin hay desde su juventud una apuesta, se podría decir, por lo esotérico y lo fragmentario, si seguimos en esto la expresión ya conocida de Adorno, y, sin embargo, no por ello se podría considerar como un pensamiento inorgánico, carente de rigurosidad o autenticidad. Lo que acontece es que el desarrollo del pensamiento de Benjamin se va desplazando -o más bien nutriendo- por distintos focos de atención, como son el teológico (de orientación judía), el estético y el político, con el claro objetivo de urdir un discurso crítico al estado de desarrollo alcanzado por la modernidad capitalista. Un estudioso de la obra de Benjamin, como es el francés Stéphane Mosès, pretende explicar el despliegue del pensamiento benjaminiano a través de la noción de "paradigma" ${ }^{11}$. Para el caso, indica Mosès, existen en el pensamiento de Benjamin tres paradigmas bien definidos. A saber, en un primer momento el teológico, luego uno de orden estético, para concluir en un paradigma político:

Benjamin aporta, a medida que va evolucionando, tres respuestas muy diferenciadas. En una primera fase, los dos textos, Sobre el lenguaje en general y sobre el lenguaje de los humanos (1916) y La tarea del traductor (escrito en 1921 y publicado en 1923), proponen un paradigma teológico de la historia. Un poco más tarde, El origen del drama barroco alemán (1923-1925, publicado en 1928) desarrolla, a propósito de la historia, un paradigma estético. En fin, a partir de los años 1925-1926, que marcan el giro marxista de Benjamin, desarrolla poco a poco un paradigma político de la historia, cuya formu-

11 Me parece que la noción de paradigma que utiliza "Mosès" se encuentra referida al trabajo de Thomas Kuhn, La estructura de las revoluciones científicas (1962). Sin entrar en mayores detalles, me parece importante consignar que la noción de "paradigma" desactiva, de ahí la importancia de su referencia ligada al caso de Benjamin, ya que no ha de entenderse el conocimiento bajo la forma de producción "lineal", ni tampoco como un "proceso acumulativo" a través del tiempo continuo. 
lación más clara se encuentra en La obra de los pasajes y en Tesis de filosofía de la historia, de 1940 (85).

Estos paradigmas, plantea Mosès, nunca se abandonan, sino que se van desplegando de manera sedimentada uno sobre el otro a través de un eje en común, que sería en este caso "la historia"12. La filósofa y ensayista Susan Sontag, en un maravilloso trabajo intitulado Bajo el signo de Saturno, reflexiona en un mismo radio de sintonía, pero complementando la perspectiva de Mosès al señalar que "Era importante para él mantener abierta sus muchas posiciones: la teológica, la surrealista/estética, la comunista (o, dicho de otro modo, la político-marxista). Una posición corrige a la otra; él las necesitaba a todas" (Sontag 143) ${ }^{13}$.

En una idea complementaria a las expresadas tanto por Mosès como por Sontag, se encuentran las de Michel Löwy quien, en coincidencia con Mosès, se esmera en sustentar la idea de que en Benjamin no hay cabida a explicar sus tópicos a partir de la noción de "sistema". En su famoso libro Aviso de incendio, en el que reflexiona en torno a las Tesis de la historia, plantea:

En Benjamin no hay sistema filosófico: toda su reflexión adopta la forma del ensayo o fragmento, cuando no de la cita pura y simple; los pasajes arrancados de su contexto se ponen al servicio de su propio uso. En consecuencia, toda tentativa de sistematización de este pensamiento poético es problemática e incierta (17).

Renuncia al sistema y, por medio del fragmento - la ruina-, hay una renuncia a cualquier tipo de interpretación manifiesta. Apuesta, siguiendo el ejercicio surrealista del montaje, a una puesta en escena en la que las significaciones actúen en su conjunto como una constelación. A través de cada fragmento sería posible reconstituir ese todo.

\section{Benjamin y el marxismo}

Además del elemento fragmentario, existe dentro de la estrategia metodológica de Benjamin una apuesta por un maridaje intelectual muy poco habitual. Tan inhabitual como fértil, como lo fue ese esfuerzo

12 A diferencia de Mosès, Terry Eagleton (1999) sostiene que la posición de Benjamin es, en todos sus órdenes, estética, y que cualquier interpretación es un malentendido.

13 (N. de A.: Los paréntesis son nuestros). 
realizado por Benjamin por mancomunar en un horizonte común el judaísmo y el marxismo. Su intención consistía básicamente en componer un aparataje crítico social con una capacidad tal que "pudiese penetrar las manifestaciones de la cultura burguesa como jeroglíficos de sus sombríos misterios: como ideología" (Adorno 251). En ese orden de cosas, su pretensión era convertirse en un arqueólogo de la modernidad, con el fin de reconocer los engranajes que han permitido a ésta haber alcanzado el estadio de desarrollo presente; pero no con el fin de que prospere en su empeño devastador, sino para aplicar el freno y hacerle saltar por los aires.

\subsection{Su arribo al marxismo}

Hay que darle razón a Stèphane Móses cuando sostiene que en el pensamiento de Benjamin acontecen tres estadios paradigmáticos, no un despliegue progresivo y lineal, sino más acorde con uno que arrastra, en el sentido que recupera de modo implícito; en una marcha que acompasa lo uno con lo otro, sin haber en cada caso una solución dialéctica. Al leer a Benjamin hay que ser consciente de que en su marxismo no hay una anulación del acervo teológico. Lo que sí es cierto es que ese arribo, al contrario del caso de muchos pensadores marxistas, no se dio a través de la puerta ancha de las obras de Marx, al menos en un principio. Su entusiasmo por el marxismo se comienza a generar a partir de 1924, luego de la lectura de Historia y conciencia de clases, del filósofo húngaro György Lukács, que había sido publicado un año antes. Una lectura a la que Benjamin había sido alentado debido a la insistente recomendación de Ernst Bloch. Lo que resulta anecdótico es que Lukács, en la tradición marxista, también va a llegar a ocupar un lugar, al igual que Benjamin: una condición de pensador heterodoxo. Esto no deja de ser interesante, ya que su primera aproximación seria al marxismo arranca de una obra, con tendencia marxista, pero al margen de la tradición heurística oficial que la sitúa en la tradición de la Tercera Internacional. Tanto es así que, en su momento, fue duramente criticada por la intelectualidad de sectores más próximos al marxismo ruso. Gershom Scholem comenta que el primer indicio de ese "giro" de Benjamin al marxismo le fue revelado en una carta que éste le había dirigido desde Capri, el 7 de julio de 1924. Por esas fechas, y en respuesta a ese "anuncio", le había puesto en antecedente el hecho de que "esta obra había sido sometida a un violento bombardeo por 
parte de los portavoces teóricos del comunismo ruso, quedando estigmatizada como una recaída en el idealismo burgués" (Scholem 2007 192). De acá en adelante hay un proceso de inmersión constante en el marxismo hasta que, a decir de muchos, se vuelve a todas luce evidente para 1934 con su escrito El autor como productor. Este encuentro con el marxismo fue asistido por varios mentores. Por ejemplo, Fritz Sternberg ${ }^{14}$ fue el primero que incentivó la inclinación, tanto a Brecht como a Benjamin, a los estudios marxistas. Esto es importante porque aporta un dato consistente al supuesto - y en extremo difundido hecho- de que la sola lectura de la obra de Lukács sería condición suficiente para explicar el inicio de Benjamin en el marxismo. Al nombre de Sternberg habría que sumar, también en condición de mentores, la influencia ejercida primero por Karl Korsch y posteriormente por Asja Lacsis, a quienes conoció en la ciudad de Capri en 1929. También el diálogo sostenido de igual forma con Brecht y Bloch, a los que posteriormente se verán sumados Adorno y Horkheimer. Es durante este periodo que Benjamin estuvo meditando su incorporación al Partido Comunista Alemán (PKD), pero su experiencia atesorada en el viaje a Moscú lo llevó a desestimar esa posibilidad y, sobre todo, a desentenderse del curso que los tópicos marxistas habían adoptado hasta ese momento en la URSS.

\subsection{Su ( $\sin )$ lugar dentro del marxismo}

Como un "advenedizo a las aguas del marxismo" podríamos calificar, tentativamente, una posible localización de Benjamin dentro de la historia de esta tradición filosófica. Un advenedizo que, por lo demás, nunca nutrió con su pensamiento la corriente dogmática y hegemónica del marxismo tradicional de cuño soviético. Es una incomodidad latente, se podría decir, que circula en un doble sentido, esto es, con carácter recíproco, porque su marxismo tiene, sobre todo, una pretensión heurística. En ese sentido, ciertas categorías del marxismo eran para él herramientas de análisis y no un catecismo ritualista ni un apostolado al que se le debe rendir pleitesía. Acerca de su posición dentro del marxismo, Benjamin califica más bien como un pensador heterodoxo respecto de las grandes tradiciones latentes a inicios del siglo XX. Ello

14 Fritz Sternberg (1895-1963) fue un sociólogo y economista marxista. 
porque, como explica Reyes Mate, "su marxismo no es corriente, el de la II ni el de la III Internacional, es decir, no se identifica ni con la socialdemocracia ni con el comunismo" (51). Benjamin critica la idea de progreso en la que se inscriben ambas tradiciones. Se mantiene a raya de ambas, porque cree ver en ellas un ciego entusiasmo por el progreso y, en ese sentido, cuestiona su potencial emancipatorio. La emancipación, según éstas, adviene como resultado de las contradicciones internas -y científicamente inevitables- del capitalismo:

Según Benjamin y su crítica al marxismo economicista, había que empezar a cuestionar como potencial emancipatorio la idea de un progreso interminable (conforme a la infinita perfección del género humano) que, como resultado de un acontecer mecánico y progresivo, irrumpiera per se en la historia (Cano 145).

En este sentido, Benjamin cree apreciar en las clásicas tradiciones de izquierda, tanto en la socialdemocracia como en los comunistas, una total incapacidad para descifrar la inherente violencia que constituye esa lógica - o ciega esperanza - del progreso. La invitación por parte de Benjamin comienza a hacerse manifiesta: "Superar el concepto de "progreso" y el de "período de decadencia", como las dos caras de lo mismo" (Benjamin 2013740 [N2, 5]). Un progreso que, en palabras de un pensador como Jürgen Habermas, recordando a Benjamin, constituiría "el eterno retorno de la catástrofe" (334). Poner a salvo a la humanidad de la catástrofe es una de las tareas que su pensamiento se propone.

\section{La estrategia teológica}

Benjamin se sirve tanto del marxismo como de la teología. Pero debe estar claro que no se sirve de cualquier teología. Su pensamiento tiene, concretamente, una organización a partir de la teología judía. Pero su experiencia con dicha tradición dista de ser ortodoxa. Debemos tener en consideración que, si bien provenía de una familia burguesa de origen judío, ésta era no practicante sino más bien "asimilada" o secularizada. La navidad, por ejemplo, era celebrada en su casa, en tanto era considerada una tradición popular alemana. Si bien para Stèphane Móses los paradigmas teológico, estético y político se suceden en una completa armonía, puesto que el componente teológico recoge al anterior sin necesidad de una síntesis dialéctica, sino más bien como 
una condición necesaria, la cual se encuentra presente en el énfasis estético, y estos dos finalmente en el paradigma político. Sin embargo, y aunque la propuesta de Mosès es muy sugerente, ésta puede ser, igualmente, puesta en tela de juicio. ¿En qué sentido? En tanto me parece que el papel de la teología juega un rol no asimilable por los otros estadios de su pensamiento, sino que más bien actúa como un campo de comprensión privilegiado, en el que los demás órdenes - estético y político- se subordinan. Al caso conviene prestar atención a lo que Benjamin declara en su obra de Los Pasajes:

Mi pensamiento está en relación con los conceptos de la teología como el papel secante con la tinta: se ha empapado de ella enteramente. Mas, si se saliera del secante, nada quedaría de mi texto (Benjamin 2013757 [N7a,7]).

Proponemos, a diferencia de otros entendidos en la obra del pensador berlinés, analizarlo a partir de un giro categórico distinto. Entenderlo, en este caso, implica sostener que Benjamin es, a buenas cuentas, una suerte de "teólogo secularizado"15. El "teólogo secularizado" opera con las categorías aportadas por la teología y, en el caso específico de Benjamin, de la teología judía de corte inspirativo de $L a$ Torá y El Talmud. En ese orden, dos cosas importantes: la primera, es que hay una suerte de carácter adversativo en la disposición metodológica de Benjamin a la hora de enfrentarse con los textos. Esto quiere decir que explora las significaciones de los textos, en la idea de tratar textos profanos "como si" fueran unos textos sagrados, sin serlos. La segunda cuestión importante consiste, como nos lo hace presente Martin Jay, en que debemos considerar que "su interés por el Talmud y la Cábala pueden así haberlo llevado a la convicción de que en cada frase existen múltiples niveles de significación" (290). Esos múltiples niveles de significación, se podría afirmar, no se aplican solo al ámbito de cada frase, sino también al aspecto metodológico. Ahí, y en esa orientación, cabría entender la propuesta interpretativa de Mòses en torno a cómo explicar el procedimiento argumentativo del pensa-

15 Esto no quiere decir que WB sea un rabino, sino que no reniega de su tradición judía. El judaísmo y las categorías políticas que éste le proporciona son lo suficientemente significativas para forzar una explicación de la historia. Una de las categorías centrales del pensamiento benjaminiano es el "ahora lejano" que se contrapone al "ahora por venir". 
miento de Benjamin, en la que cada "nivel" (teológico, estético y político) se complementan y nunca se superan dialécticamente. En este caso, la "teología secularizada" opera con la misma lógica que una vacuna, es decir, como la cepa inoculada de un determinado "virus" que es introducido a un cuerpo concreto. Los principios activos del virus han sido previamente desactivados, con el exclusivo fin de aportar al cuerpo en cuestión los antecedentes estructurales de un peligro latente. El objetivo sería, entonces, proveerle de las condiciones necesarias para una lucha efectiva. El cuerpo queda, a partir de ese momento, en un estado de alerta.

Entonces, la secreta estrategia del pensamiento benjaminiano consistiría en la necesidad de ocultar el "paradigma teológico" ${ }^{16}$. Utiliza a su favor tanto los motivos estéticos como los motivos marxistas. Ambas -la estética y la política- se encuentran supeditadas al ámbito teológico. En sintonía con lo expresado ahora último, Andreas Pangritz señala que "el pensamiento de Benjamin muestra ser teológico en su núcleo oculto" (1173), más allá del ropaje que asume en determinado momento, sea ya el estético o bien el político, puesto que, al fin y al cabo, Benjamin se sirve de ambos.

La estrategia de Benjamin bien puede ser explicada a partir de un pasaje alegórico de ese "testamento intelectual" de 1940 conocido como Las Tesis de la Historia. Al final de la primera tesis podemos leer: [El autómata jugador de ajedrez] "Puede competir sin más con cualquiera siempre que ponga a su servicio a la teología, la misma que hoy, como se sabe, además de ser pequeña y fea, no debe ser vista por nadie" (2008 35 [tesis 1]). Por un lado, de esta tesis se desprende una crítica al materialismo ortodoxo. Si consideramos los acontecimientos políticos hasta esa fecha, el gran enemigo, el fascismo, no ha dejado de triunfar (Id. 40 [tesis 6]). Alemania, Italia y España dejaron en evidencia que la estrategia de "ese materialismo" ha resultado ineficiente. La forma de triunfar es instalar en el corazón del materialismo dialéctico a la teología como motor, puesto que solo así podrá triunfar. ¿Qué sig-

16 Sin duda que este punto en específico resulta capital para la comprensión y articulación del pensamiento benjaminiano. Un desarrollo satisfactorio, y de esto somos plenamente conscientes, requiere, a nuestro entender, de un trabajo que se dedique de modo detallado. En esta oportunidad solo ofrecemos los lineamientos generales con el fin de perfilar este asunto. Esperamos prontamente hacernos cargo de este desafío. 
nifica para Benjamin la teología? Fundamentalmente dos cosas: rememoración (Eingedenken) y redención mesiánica (Erlösung). ¿Por qué le interesa el marxismo? Porque, como explica Reyes Mate:

Lo que le interesa del marxismo es un sentido práctico de la verdad, es decir, que la verdad es justicia. El marxismo establece una relación entre conocimiento e interés, dejando al descubierto la falsa inocencia de todo conocimiento. Si eso es así, sólo cabría hablar de conocimiento verdadero cuando estuviera en función del interés general. ¿Existe ese interés? Existe: es la negación de la injusticia (53).

El enano jorobado, pequeño y feo no debe ser visto. $Y$ sin embargo debe ser capaz, a través de esa invisibilidad, de dar vida al muñeco que mueve las piezas para así ganar la partida. La teología es el corazón de la estrategia por medio de la cual pone a su servicio, tanto en un caso como en otro, al marxismo o a la estética, porque la redención mesiánica acontece en la historia. La estrategia es teológica y el motivo, podríamos decir, es la historia.

\section{Bibliografía}

Adorno, Theodor. "Caracterización de Walter Benjamin". Prismas. La crítica de la cultura y de la sociedad. Traducción de Manuel Sacristán. Barcelona: Ediciones Ariel, 1962.

Arendt, Hannah y Scholem, Gershom. Tradición y política. Correspondencia (1939-1964). Traducción de Linda Maeding y Lorena Silos. Madrid: Editorial Trotta, 2018.

Arendt, Hannah. Hombres en tiempos de oscuridad. Traducción de Claudia Ferrari y Agustín Serrano. Barcelona: Gedisa Editorial, 2008.

Benjamin, Walter y Scholem, Gershom. Correspondencia 1933-1940. Traducción de Francisco Lupiani. Madrid: Editorial Trotta, 2011.

Benjamin, Walter y Adorno, Theodor. Correspondencia 1928-1940. Traducción de Jacobo Muños Veiga y Vicente Gómez Ibáñez. Madrid: Editorial Trotta, 1998.

Benjamin, Walter. Tesis sobre la historia. México: Editorial ÍtacaUACM, 2008.

Benjamin, Walter. Obras. L. II /Vol. 2. Madrid: Abada Editores, 2009. 
Benjamin, Walter. "Obras de los pasajes [Vol. 1]". Obras. L. V/ Vol. 1. Madrid: Abada Editores, 2013.

Benjamin, Walter. "Diálogos sobre la religiosidad del presente". Obras. L. II/ Vol. I. Madrid: Abada Editores, 2007.

Benjamin, Walter. "Infancia en Berlín hacia 1900". Obras, Libro IV, Vol. 1. Madrid: Abada Editores, 2010.

Cano, Germán. Nietzsche y la crítica de la modernidad. Madrid: Editorial Biblioteca Nueva, 2001.

Eagleton, Terry. Walter Benjamin o hacia una crítica revolucionaria. Traducción de Julia García Lenberg. Madrid: Ediciones Cátedra, 1999.

Eilenberger, Wolfram. Tiempos de Magos. La gran década de la filosofía 1919-1929. Traducción de Joaquín Chamorro Mielke. Bogotá: Editorial Taurus, 2019.

Habermas, Jürgen. "Entre arte y política: Un careo con Walter Benjamin". Revista de Occidente, 129/ Diciembre, Madrid, 1973.

Husserl, Edmund, Investigaciones lógicas, 1. Traducción de E. Taberning. Madrid: Alianza Editorial, 1999.

Husserl, Edmund. La fenomenología como ciencia estricta. Traducción de José Gaos y González Pola. Buenos Aires: Editorial Nova, 1962.

Jay, Martin. La imaginación dialéctica, Una historia de la escuela de Frankfurt. Traducción de Juan Carlos Curutchet. Madrid: Editorial Taurus, 1988.

Löwy, Michael. Walter Benjamin. Aviso de incendio. Traducción de Horacio Pons. Buenos Aires: Editorial FCE, 2005.

Marinas, José Miguel y Santamarina, Cristina. El bazar americano. En las exposiciones universales. Madrid: Editorial Biblioteca Nueva, 2015.

Meyer, Hans. Walter Benjamin. El contemporáneo. Traducción de Gustau Muñoz. Valencia: Edicions Alfons el Magnànim, 1992.

Mosès, Stéphane. El ángel de la historia. Rosenzweig, Benjamin, Scholem. Traducción de Alicia Martorel. Madrid: Editorial Cátedra, 1997.

Pangritz, Andreas. “Teología”. Opitz, Michael y Wizisla, Erdmut. Conceptos de Walter Benjamin. Traducción de María Belforte y Miguel Vedda. Buenos Aires: Editorial Las Cuarenta, 2014. 
Reyes Mate, Manuel. Medianoche en la historia. Comentarios a las tesis de Walter Benjamin "Sobre el concepto de historia". Madrid: Editorial Trotta, 2009.

Scholem, Gershom. Walter Benjamin y su ángel. Traducción de Ricardo Ibarlucía y Laura Carugati. Buenos Aires: FCE, 1998.

Scholem, Gershom. Walter Benjamin. Historia de una amistad. Traducción de J. F. Yvars, Madrid: Ed. Debolsillo, 2007.

Sontag, Susan. Bajo el signo de Saturno. Traducción de Juan Utrilla Trejo. Barcelona: Ed. Debolsillo, 2007.

Traverso, Enzo. Cosmópolis. Figuras del exilio judeo-alemán. Traducción de Silvana Rabinovich. México: Ed. Universidad Autónoma de México, 2004.

Weitz, Eric. La Alemania de Weimar. Presagio y tragedia. Traducción de Gregorio Cantera. Madrid: Editorial Turner Noema, 2009.

Witte, Bernd. Walter Benjamin. Una biografía. Traducción de Alberto L. Bixio. Barcelona: Gedisa Editorial, 2002. 